\title{
O ARGUMENTO BAYESIANO DA EXPERIÊNCIA RELIGIOSA EM FAVOR DO TEÍSMO *
}

\author{
The Bayesian Argument from Religious Experience to Theism
}

Agnaldo Cuoco Portugal **

Resumo: $\mathrm{O}$ artigo apresenta e discute criticamente o argumento da experiência religiosa proposto por Richard Swinburne na obra The Existence of God (2004), uma das mais importantes da filosofia analítica da religião contemporânea. Além de introduzir conceitos de teoria da indução probabilística, que servem de base para o argumento proposto, são também explicados os elementos de teoria da percepção e da justificação de crenças perceptuais que Swinburne supõe. Em seguida, são discutidos quatro questionamentos possíveis contra o argumento da experiência religiosa. Por fim, consideram-se duas respostas possíveis aos questionamentos feitos na parte anterior, de modo a se poder ainda empregar o fenômeno da experiência religiosa no debate acerca da existência de Deus de modo argumentativo.

Palavras-chave: Experiência religiosa. Argumento indutivo. Bayesianismo. Richard Swinburne.

Abstract: The article presents and critically discusses Richard Swinburne's argument from religious experience presented in The Existence of God (2004), one of the most important works in contemporary analytic philosophy of religion.

\footnotetext{
* Agradeço à FINATEC (Fundação de Empreendimentos Científicos e Tecnológicos) pelo auxílio que me permitiu participar do V Congresso da Sociedade Brasileira de Filosofia Analítica, em Salvador-BA, 10 a 14/9/2018, onde apresentei o presente trabalho.

** Doutor em Filosofia da Religião pelo King's College da Universidade de Londres. Professor do Departamento de Filosofia da Universidade de Brasília e do PPG-FIL/UnB. Artigo recebido em 22/03/2019 e aprovado para publicação em 11/01/2020.
} 
The argument proposed rests on some concepts of the probabilistic theory of induction that are introduced here. The paper then explains elements of the perception theory as well as the theory of justification of perceptual beliefs, which are supposed by Swinburne. Next, it discusses four challenges against his argument from religious experience. In the last section, two answers to the challenges are considered, so that the phenomenon of religious experience can still be employed in the debate about the existence of God in an argumentative way.

Keywords: Religious experience. Inductive argument. Bayesianism. Richard Swinburne.

\section{Introdução}

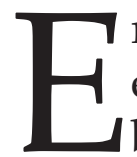
$\mathrm{m}$ The Existence of God ${ }^{1}$, Richard Swinburne traz o argumento da experiência religiosa como o último da sequência de inferências probabilísticas indutivas cumulativas apresentadas em favor da tese da existência de Deus, concebida segundo o teísmo tradicional (inspirado nas três grandes religiões monoteístas). Probabilidade é um conceito que pode ser entendido de mais de um modo. Esse autor apresenta ${ }^{2}$ três concepções distintas. A probabilidade física ou propensão se refere ao grau no qual um evento é pré-determinado por suas causas em dado tempo anterior. A probabilidade estatística é definida como uma proporção de eventos, seja em vista de uma classe já definida seja de uma classe hipotética - gerável por um processo repetitivo. A probabilidade indutiva é a medida do quanto uma proposição torna outra provavelmente verdadeira. A discussão aqui se refere a esta última concepção de probabilidade, também chamada de "epistêmica".

"Experiência religiosa" nesse argumento é um conteúdo mental tido como causado pela manifestação de um ser divino ou relacionado a um ser divino. $\mathrm{O}$ argumento da experiência religiosa pretende tomar relatos de alegadas experiências desse tipo como indício ${ }^{3}$ em favor do teísmo. Em

\footnotetext{
${ }^{1}$ SWINBURNE, Richard. The Existence of God - Second Edition. Oxford: Oxford University Press, 2004. A primeira edição foi publicada pela mesma editora em 1979, com uma revisão em 1991.

2 SWINBURNE, Richard. Epistemic Justification. Oxford: Clarendon, 2001. P. 56-62.

${ }^{3} \mathrm{O}$ termo usado em inglês nessa discussão é evidence, que prefiro não traduzir por "evidência", pois esse substantivo em português denota uma qualidade do que é evidente, algo que não se pode pôr em dúvida, o que não é o caso de uma evidence em inglês, que pode ser questionada. Daí a preferência pelo termo "indício", embora reconheça que ele soe um tanto fraco, mas mesmo assim parece melhor que "prova", que é forte demais, principalmente em se tratando de um contexto de argumentos indutivos e probabilísticos. Cabe, então, qualificar o termo com expressões como "fraco", "forte", "bastante forte" etc. para indicar que se trata de uma questão de grau. Em todo caso, porém, o leitor pode substituir mentalmente "indício" por "evidência" se achar mais conveniente.
} 
termos probabilísticos bayesianos, isso significa que esses relatos confirmam a tese teísta ao aumentar seu grau de probabilidade prévia ao considerar esse indício. Isso significa dizer que esses relatos (indícios $e$ ) se tornam mais prováveis em vista do teísmo (hipótese $h$ ) do que da negação do teísmo $(\sim h)$, considerando-se $k$ o conhecimento de fundo (o conjunto de afirmações empíricas e a priori levadas em conta na avaliação comparativa da hipótese), temos o seguinte no teorema de Bayes:

$$
P(h \mid e \wedge k)=\frac{P(e \mid h \wedge k) P(h \mid k)}{[P(e \mid h \wedge k) P(h \mid k)]+[P(e \mid \sim h \wedge k) P(\sim h \mid k)]}
$$

Na expressão acima, " $\Lambda$ " é o símbolo da conjunção, e a barra reta "|" é lida como "dado que". Assim $P(h \mid e \wedge k)$ deve ser lido como "a probabilidade da hipótese $h$ dados o indício $e$ e o conhecimento de fundo $k^{\prime \prime}$ Elemento essencial do argumento de Swinburne é a passagem da experiência religiosa como relato de um conteúdo mental para asserção acerca de uma realidade extramental que se manifestou ao agente perceptivo e que teria supostamente causado sua experiência. Sem fundamentar essa passagem, pode-se explicar o indício em questão simplesmente como um fato da vida psicológica do agente apenas, ou seja, a hipótese teísta não traria ganho de inteligibilidade ao indício; em termos formais:

$P(e \mid h \wedge k)<P(e \mid \sim h \wedge k)$.

Essa fundamentação se dá, segundo ele, pelo "princípio de credulidade": "[...] (na ausência de considerações especiais) se parece (epistemicamente) a um sujeito que $x$ está presente, então provavelmente $x$ está presente, $\mathrm{o}$ que alguém parece perceber é provavelmente do modo percebido" ${ }^{4}$.

Trata-se de um princípio bastante forte, que obviamente contraria o ceticismo em relação à possibilidade de cognição por meio da experiência. Swinburne está ciente disso e argumenta que o princípio de credulidade é exatamente para evitar que se caia em um "atoleiro cético" quando se tem uma percepção de algo. Normalmente, nas ciências naturais ou em contextos comuns inclusive, se nos parece que algo está presente, então acreditamos que provavelmente esse algo está presente ${ }^{5}$.

\footnotetext{
${ }^{4}$ SWINBURNE, Richard. The Existence of God. Oxford: Oxford University Press, 1991, p. 254.

${ }^{5}$ Um dos pareceristas indagou se "possivelmente" não seria mais adequado do que "provavelmente" neste caso. Considerando o contexto da proposta de Swinburne, não estaria errado, mas seria fraco demais. O que ele pretende é enunciar um princípio forte o suficiente para dar conta do ceticismo quanto à possibilidade de acesso à realidade externa à própria experiência.
} 
Mas pode ser que o caso não seja normal, ou seja, que estejamos em uma situação especial na qual o princípio de credulidade deixa de valer. Essas seriam de quatro tipos básicos: duas delas se referem a circunstâncias nas quais relatos perceptuais se mostraram inconfiáveis no passado, ou do ponto de vista do sujeito, ou do ponto de vista do objeto. As outras duas restrições se referem à causalidade entre o objeto supostamente percebido e a percepção: se o conhecimento de fundo informa que o objeto da percepção provavelmente não estaria presente, então essa é uma circunstância para duvidar da crença formada perceptualmente. Além disso, e por fim, se há razão para pensar que foi provavelmente outra a causa daquilo que foi percebido, então, temos outra situação limitadora.

Outra maneira de apresentar esses casos limitadores da aplicação do princípio de credulidade é explicitando o pressuposto da teoria da percepção que está sendo considerada. Esses pressupostos são os seguintes:

1. Descrição interna da percepção: $S$ forma a crença $p$ de que $x$ causou sua percepção.

2. Teoria causal da percepção: um sujeito $S$ percebe $x$ conscientemente se e somente se uma experiência de $x$ para $S$ foi causada pela presença de $x$;

“Descrição interna" de uma percepção significa apresentá-la como fenômeno mental de alguém e não como descrição do objeto percebido. O pressuposto 1. se justifica porque o que se tem inicialmente é a afirmação de alguém de que percebeu algo e o problema é justificar que essa percepção é indício de que o objeto descrito estava presente. Assim, ao invés de dizer "há uma árvore lá fora", a descrição interna é "percebo uma árvore lá fora" e a tarefa de fundamentação é mostrar que essa percepção é indício para a presença da árvore.

A teoria causal pretende explicar a percepção afirmando que aquilo que a distingue de uma alucinação ou ilusão é o fato de que a causa da percepção é o objeto descrito pelo sujeito e não outro ente, ou mesmo algum evento psicológico interno. Assim, eu realmente vejo um copo d'água no deserto se a causa do meu evento mental visual é de fato um copo d'água e não uma miragem ou algum outro objeto.

Desse modo, as condições especiais de limitação do princípio de credulidade seriam razões para pensar que o objeto alegado como percebido pelo sujeito não foi aquilo que causou a pretensa percepção, pois ele não existe, ou não existe mais; o objeto alegado existe, mas não estava presente; ou o objeto existe, estava presente, mas não foi a causa da percepção do sujeito. Assim, minha afirmação de que vi uma árvore lá fora pode ser negada como razão para acreditar que há uma árvore lá fora se não existir nenhuma árvore naquele lugar; se existiu, mas não existe mais; se ela existe, mas não estava no lugar que pensei que estava; se ela existe, 
estava presente, mas não foi uma árvore que causou minha percepção, mas sim um banner com uma foto de uma árvore, por exemplo.

Para Swinburne, no caso das alegadas percepções de Deus e nas experiências religiosas de outros tipos, não há porque pensar que elas caem todas nas circunstâncias especiais acima. Os casos nos quais se pode atribuir a crença perceptual religiosa a algum problema no agente perceptivo (estar sob o efeito de drogas, por exemplo) não são os mais comuns. Em segundo lugar, Deus não poderia se manifestar numa experiência apenas se não existisse, e não há argumento forçoso nesse sentido ainda. Em terceiro lugar, se Deus existe conforme afirma o teísmo, Ele é onipresente e será percebido segundo a capacidade de quem o percebe e conforme Sua vontade de se manifestar mais claramente. Por fim, sendo a causa fundamental de tudo, a quarta limitação não se aplica ao caso da percepção teísta, pois se Deus existir e estiver presente, será a causa da percepção do sujeito que relata a experiência.

No entanto, mesmo em vista dessas considerações de Swinburne, podemos ainda fazer os seguintes questionamentos: 1) as diferenças entre experiência religiosa e percepção sensível não seriam suficientes para negar a aplicação do princípio de credulidade às alegadas percepções teístas?; 2) as explicações naturalistas das experiências religiosas não diminuem consideravelmente seu poder confirmatório?; 3) a diversidade religiosa não coloca problemas muito sérios para a identificação dessas supostas experiências como sendo referentes a Deus?

No presente artigo, vou desenvolver melhor as considerações acima, analisar essas objeções e fazer uma avaliação do argumento da experiência religiosa proposto por Swinburne.

\section{Experiência Religiosa e Raciocinio Indutivo Probabilista}

Richard Swinburne vê no fenômeno da experiência religiosa um indício que, incrementa a probabilidade da hipótese da existência de Deus. Sua proposta é a formulação de um argumento com base na ocorrência de experiências religiosas que ajude a tornar provável a tese de que Deus existe. Para isso, Swinburne recorre a um aparato teórico-formal fornecido pela teoria da probabilidade aplicada à interpretação do raciocínio indutivo. Segundo este filósofo, o grau de uma crença é justificado se os indícios relevantes (que a favorecem ou que a desfavorecem) forem de tal modo que, no balanço final, dadas certa interpretação dos dados considerados e regras de indução e de racionalidade, esses indícios conduzirem ao resultado de ela ser mais provável que a sua negação. Exemplificando para 
tentar tornar mais claro, pensemos numa situação em que os dados $A$ e $B$ levam a pensar que quem matou uma vítima foi o mordomo, mas os eventos $C$ e $D$ fazem pensar que foi o filho da vítima. Se essas forem as únicas hipóteses e forem incompatíveis, a crença na hipótese do mordomo estará justificada se o grau com o qual $A$ e $B$ a favorecerem for maior do que o grau com o qual $C$ e $D$ favorecem a hipótese do filho. Nesse caso, estamos dizendo que a hipótese do mordomo explica melhor o conjunto de todos os fatos envolvidos (embora principalmente $A$ e $B$ ) do que o faz a tese rival.

O mecanismo desse tipo de raciocínio indutivo, segundo Swinburne, é bem captado por um dos teoremas do cálculo de probabilidades, o teorema de Bayes. Admitindo-se a ideia de se atribuir valores probabilísticos a hipóteses ou crenças, esse teorema nos diz que o grau de confirmação de uma hipótese é dado pela estimativa prévia de sua probabilidade e pelo seu poder explicativo em relação aos dados relevantes para a sua avaliação. Assim, o detetive que está tentando descobrir o autor do crime, parte da estimativa inicial de uma das hipóteses rivais e considera o quanto esta explica os dados disponíveis, conforme a fórmula abaixo, que é uma variante da que foi exposta na introdução:

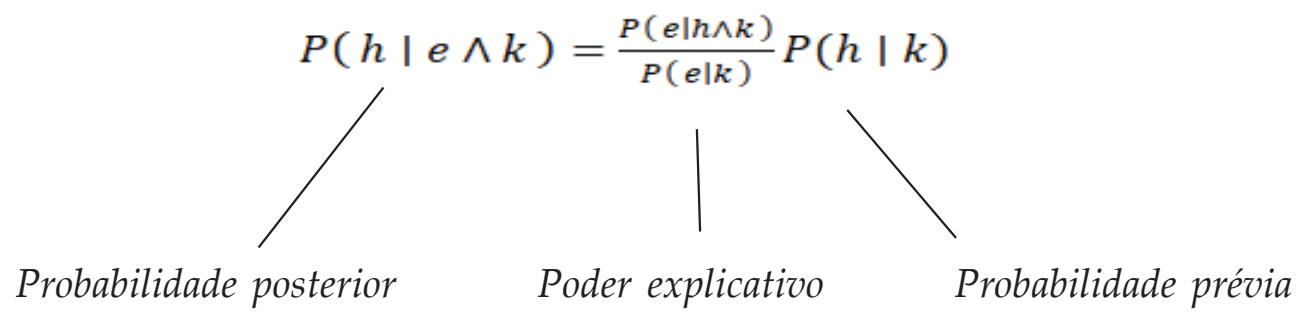

A "probabilidade posterior" de uma hipótese $h$ é seu valor após calculadas a probabilidade prévia e o poder explicativo estimado da hipótese em relação aos dados relevantes. É o resultado a que queremos chegar, pois se refere à probabilidade de $h$ que estamos analisando em vista dos eventos $e$ que forem relevantes para sua avaliação e do conhecimento de fundo $k$, ou seja, tudo o mais que pressupomos acerca de como as coisas são. A probabilidade posterior de uma hipótese define o grau de crença que estamos justificados em ter acerca dessa hipótese. Esse grau justificado de crença é dado, então, por um lado, pelo grau em que os eventos são explicados pela hipótese e, por outro, pelo grau de plausibilidade prévia da hipótese, sem considerar seu poder explicativo.

Esse esquema inferencial, que parece funcionar bem para raciocínios indutivos na vida cotidiana e na avaliação de hipóteses científicas, Swinburne propôs aplicar na discussão da racionalidade da crença de que Deus existe. Basicamente, os argumentos tradicionais da teologia natural 
e alguns outros que ele formula são traduzidos em termos de inferências pela melhor explicação no sentido de que certos fenômenos (a existência do universo, a existência de ordem no universo, a existência de seres conscientes, etc.) são mais bem entendidos considerando-se a tese de que Deus existe. O lugar da experiência religiosa na epistemologia da crença teísta de Swinburne é de outro fenômeno que é mais bem explicado pela tese de que existe um Deus tal como postulado pela crença comum das grandes religiões monoteístas (um ser pessoal incorpóreo, onipotente, onisciente, perfeitamente bom, onipresente, eterno e digno de adoração). $\mathrm{Na}$ verdade, trata-se não apenas de "mais um fenômeno", mas do argumento decisivo em favor do teísmo, que faz o balaço final de probabilidade, com o qual ele conclui seu livro mais importante, The Existence of God, pender em favor da tese de que Deus existe ${ }^{6}$.

Para Swinburne, uma experiência é uma ocorrência mental consciente, que pode ser descrita de modo a acarretar a existência do objeto lógico - ou seja, aquilo do que se fala - ao qual se refere (descrição externa) ou apenas se referindo ao evento mental mesmo (descrição interna) ${ }^{7}$, conforme indicamos na introdução.

Em sua análise da experiência religiosa, Swinburne opta pelo caminho mais difícil, ou seja, por uma epistemologia que adote uma descrição interna da experiência e que proponha critérios para justificar a passagem daquilo que parece para o sujeito para aquilo que existe objetivamente (e que o sujeito alega perceber). Se adotasse uma descrição externa da experiência religiosa, não haveria necessidade de argumento algum, pois o foco da descrição seria o próprio objeto lógico ao qual ela se refere, ou seja, Deus ${ }^{8}$ e a vivência dessa experiência já seria imediatamente a da presença de Deus. Ao partir de uma descrição interna da experiência religiosa, porém, Swinburne leva em consideração a tese dos céticos em relação à experiência religiosa de que tais relatos apenas descrevem o que se passa na mente das pessoas que os narram, que não são prova da existência de realidade alguma independente da mente delas. Isso não significa que ele concorde com o cético. Seu propósito é mostrar que, mesmo se partindo de uma descrição interna da experiência religiosa, a melhor maneira de se entendê-la é mesmo como referindo-se a Deus e não a uma mera construção mental humana. Além disso, essa "concessão" ao cético é bastante coerente com seu projeto intelectual em filosofia da religião em geral que é o de argu-

\footnotetext{
${ }^{6}$ SWINBURNE, Richard. The Existence of God - Second Edition. Oxford: Oxford University Press, p. 341-2.

7 SWINBURNE, Richard. The Existence of God - Second Edition. Oxford: Oxford University Press, p. 293-4.

${ }^{8}$ É importante notar que não se trata aqui de tomar Deus como um objeto no sentido de uma coisa entre outras, mas como referência da experiência e daquilo que se diz dessa experiência, daí a ênfase no qualificativo "lógico" da palavra "objeto" nesse contexto.
} 
mentar em favor do teísmo usando a linguagem mais próxima possível da que se usa no raciocínio científico e partindo de pressupostos os mais aceitáveis possíveis para os participantes do meio acadêmico-científico, que ele avalia como majoritariamente agnóstico ou ateu9 .

Swinburne se concentra na análise de um tipo específico de experiência, a percepção. O termo experiência de fato é bastante amplo e pode incluir sentimentos que têm pouco ou nenhum conteúdo informativo, como alegria ou angústia, por exemplo. Em se tratando de uma epistemologia da experiência religiosa, a escolha se justifica, uma vez que o interesse se volta para o aspecto cognitivo envolvido nesse fenômeno. Segundo Swinburne, "Perceber' é o verbo geral para a consciência de algo além de si mesmo, que pode ser mediada por algum dos sentidos comuns - por exemplo, pode ser uma questão de ver ou ouvir ou degustar - ou por nenhum destes" (Swinburne 2004, 296). Assim, o que se terá em questão aqui é a experiência religiosa enquanto percepção de Deus no sentido de consciência de sua presença ou de sua ação reais, por oposição a uma simples ocorrência mental que não tenha correspondente ontológico para além dos meros sentimentos humanos envolvidos. Em outras palavras, Swinburne tem um pressuposto ontológico realista em sua epistemologia da experiência religiosa, entendendo-se por realismo a tese de que o objeto lógico a que se referem os relatos dessas experiências não é meramente uma construção linguística, mas tem uma realidade independente e anterior à linguagem humana.

O tipo de realismo da análise de Swinburne fica mais claro na teoria da percepção que ele propõe. Por um lado, é adotada uma noção causal da relação entre o objeto lógico e a percepção do sujeito, delineada na introdução. Segundo a teoria causal, um sujeito $S$ percebe $x$ conscientemente se e somente se uma experiência de $x$ para $S$ foi causada pela presença de $x^{10}$. Mas esse realismo direto, que vincula causalmente a percepção do sujeito e o objeto lógico percebido, é mitigado pela abordagem epistêmica das proposições perceptuais (aquelas que envolvem o verbo "parecer" e seus sinônimos) adotada pelo autor e já indicada acima. Em outras palavras, em sua descrição interna, uma proposição perceptual não é uma prova direta do objeto lógico percebido, mas se refere ao que o sujeito está inclinado a acreditar com base em sua experiência perceptual presente ${ }^{11}$. Assim, o fato de $x$ ter causado a percepção de $S$ é aquilo que $S$ está propenso a acreditar no momento da percepção, mas sua crença pode se revelar fal-

\footnotetext{
9 SWINBURNE, Richard. "Intellectual Autobiography", in: PADGETT, Alan. Reason and the Christian Religion. Oxford: Clarendon, 1994, p. 1.

${ }^{10}$ SWINBURNE, Richard. The Existence of God - Second Edition. Oxford: Oxford University Press, p. 296.

${ }^{11}$ SWINBURNE, Richard. The Existence of God - Second Edition. Oxford: Oxford University Press, p. 295.
} 
sa e carente de revisão em vista de considerações para além da própria percepção. Isso cria uma lacuna entre o que o sujeito percebe e o que ele está justificado em acreditar com base na percepção. Uma percepção de $S$ que parece ter sido causada por $x$ pode se revelar posteriormente não passar de uma alucinação ou de uma ilusão.

\section{Justificação Indutiva de uma Crença Perceptual Religiosa}

Assim, a epistemologia da experiência religiosa de Swinburne necessita não apenas de uma teoria da percepção de Deus, mas também de uma teoria da justificação das crenças perceptuais em geral que se aplique à crença gerada por esse tipo de percepção. A teoria da justificação de crenças perceptuais de Swinburne, em sua aplicação ao caso da experiência religiosa (ou seja, a justificação da crença de que Deus existe com base em relatos de percepções de Deus), consiste de três elementos: critérios básicos de indução probabilística, retratados no teorema de Bayes, e dois princípios indutivos adicionais, o princípio de credulidade e o princípio de testemunho.

Do teorema de Bayes já falamos brevemente e para os propósitos deste trabalho basta esclarecer os três sentidos básicos pelos quais uma crença pode ser sustentada de modo justificado num determinado grau, segundo a teoria bayesiana da racionalidade. Em primeiro lugar, o grau de crença deve ser coerente, obedecendo os axiomas do cálculo de probabilidade. Assim, se é atribuído um grau 0,7 para a crença na hipótese de que quem matou a vítima foi o mordomo e, uma vez que a única alternativa considerada seja a de que o assassino era o filho da vítima e que ambas hipóteses sejam excludentes, o grau de crença na hipótese do filho deve ser 0,3 , pois, do contrário se estará desobedecendo o primeiro axioma do cálculo que implica que o valor total de uma probabilidade não pode ser maior do que 1 nem menor que zero. ${ }^{12}$ Em segundo lugar, como corolário da ideia anterior, o grau de probabilidade da crença deve mudar de forma

\footnotetext{
${ }^{12}$ A atribuição de valores numéricos à estimativa da probabilidade de crenças não é tarefa simples e pode soar artificial. É preciso reconhecer esses limites, que são análogos às perdas semânticas e à artificialidade resultante da redução da linguagem natural aos termos da lógica formal dedutiva moderna. Porém, assim como a formalização da linguagem natural em termos lógicos permite um maior rigor no controle das conclusões que se extraem das premissas admitidas e uma maior operacionalidade no manejo das afirmações que se fazem, o mesmo pode ser dito da atribuição de probabilidades numéricas aos graus de crença. Quanto à artificialidade, trata-se de um problema muito parecido ao do professor que tem de atribuir uma nota numérica a uma prova ou um trabalho de filosofia, ou seja, nada mais é que uma aproximação útil.
} 
correspondente aos fatores relevantes à hipótese em avaliação. Em outras palavras, em vista de um fato ou argumento que confirme ou infirme a hipótese em avaliação, a probabilidade posterior desta deve consequentemente aumentar ou diminuir e quando um novo fato ou argumento for trazido à baila, a nova probabilidade prévia da hipótese deverá ter o valor resultante (a probabilidade posterior) em vista do fato ou argumento anterior. Em termos formais, temos algo assim, com uma acumulação de novos indícios $\left(e_{n}\right)$ sendo levados em conta na avaliação da probabilidade da hipótese $h$ :

$$
\begin{aligned}
& P\left(h \mid e_{1} \wedge k\right)=\frac{P\left(e_{1} \mid h \wedge k\right)}{P\left(e_{1} \mid k\right)} P(h \mid k) \\
& P\left(h \mid e_{1} \wedge e_{2} \wedge k\right)=\frac{P\left(e_{2} \mid h \wedge e_{1} \wedge k\right)}{P\left(e_{2} \mid e_{1} \wedge k\right)} P\left(h \mid e_{1} \wedge k\right) \\
& P\left(h \mid e_{1} \wedge e_{2} \wedge e_{3} k\right)=\frac{P\left(e_{3} \mid h \wedge e_{1} \wedge e_{2} \wedge k\right)}{P\left(e_{3} \mid e_{1} \wedge e_{2} \wedge k\right)} P\left(h \mid e_{1} \wedge e_{2} \wedge k\right)
\end{aligned}
$$

Essa é normalmente conhecida como a "regra do condicionamento" e dá um caráter dinâmico à coerência. Isso significa que, nessa concepção de racionalidade, a insistência na manutenção de um grau de crença numa hipótese, de um modo que não reconheça fatos e argumentos que o fortaleçam ou enfraqueçam é uma atitude irracional, à qual se qualifica geralmente como "preconceito"13. O terceiro elemento da concepção bayesiana de racionalidade e que está de certa forma pressuposto nos anteriores, é a tese de que o grau de crença numa determinada ideia deve ser proporcional à sua probabilidade prévia e ao seu poder explicativo. Assim, por exemplo, se após a consideração dos dados e argumentos relevantes a uma certa ideia chega-se a uma probabilidade epistêmica de 0,3 , deve-se admitir que se trata de uma tese improvável em relação à sua negação, ou seja, a tese é improvável em geral ${ }^{14}$.

\footnotetext{
${ }^{13}$ Assim, "preconceito" deve ser distinto de "opinião prévia", entendendo-se esta última como o grau de onde se parte na avaliação de uma ideia. Um preconceito é uma opinião prévia que é imune aos fatores que o próprio sujeito que o adota entende serem suficientes para alterá-lo. Nessa interpretação, trata-se, então, de uma incoerência, daí sua irracionalidade. ${ }^{14}$ Por vezes, porém, a negação de uma tese consiste não apenas de uma hipótese, mas de muitas. Nesse caso, se uma hipótese tiver 0,3 de probabilidade, ela será menos provável que sua negação, mas pode ser mais provável que cada uma de suas rivais consideradas individualmente.
} 
O princípio de credulidade é tido por Swinburne como um critério fundamental para que uma experiência descrita de modo interno tenha relevância cognitiva, isto é, não seja considerada meramente uma ocorrência mental do sujeito, mas um indício bastante forte de que o objeto ao qual ela se refere existe de forma ontologicamente independente. Tal princípio pode ser formulado assim: "na ausência de considerações especiais, se parece a um sujeito $S$ que $x$ está presente, então $x$ está presente"15. Em outras palavras, ao contrário da posição cética, o princípio de credulidade afirma que a experiência perceptual tem o benefício da dúvida, sendo "inocente até que se prove o contrário" no tocante à sua confiabilidade em nos informar a respeito do que há em uma coordenada de espaço e tempo determinada e das características disso que é percebido. Isso obviamente não significa que uma crença perceptual não possa estar errada e é isso que se quer ressalvar com a expressão "na ausência de considerações especiais".

Segundo Swinburne, há quatro tipos básicos dessas considerações que anulam ou diminuem a confiabilidade de uma crença perceptual particular. Primeiramente, tem-se a constatação de que a alegada percepção foi feita em condições relativas ao sujeito ou por alguém que no passado não se revelaram confiáveis ${ }^{16}$. Se o sujeito que apresenta o relato de experiência religiosa é alguém que no passado se mostrou em repetidas situações um mentiroso contumaz ou se estava sob o efeito de substâncias que distorcem a capacidade de percepção, então tem-se aqui uma razão para não aplicar o princípio de credulidade. A segunda consideração especial refere-se a problemas em relação ao objeto percebido que, por motivo de dificuldade de ser reconhecido por parte daquele sujeito ou porque há razões para crer que o objeto não existe ou não existe mais, conduzem à tese de que é mais racional não aplicar o princípio de credulidade a essas alegadas percepções. Assim, cabe pôr em dúvida a crença de que vimos na rua alguém que sabemos que já morreu. Diante dessa informação, é melhor pensar que se tratava de uma alucinação. Em terceiro lugar, podemos pôr em dúvida uma suposta percepção quando, dadas certas informações de fundo, é provável que o objeto não estivesse presente para causar a percepção do sujeito. No exemplo anterior, se constatamos haver um sósia que podia estar no local onde pensamos que vimos a pessoa que morreu, teremos razão para aceitar que houve de fato uma percepção, mas enganosa, pois o que estava presente não era o objeto que pensávamos que fosse e sim outro. Por fim, Swinburne sugere que uma quarta condição para não se aplicar o princípio de credulidade a uma percepção é a situação na qual se reconhece que o objeto pudesse até estar presente, mas que provavelmente

\footnotetext{
${ }^{15}$ SWINBURNE, Richard. The Existence of God - Second Edition. Oxford: Oxford University Press, p. 303.

${ }^{16}$ SWINBURNE, Richard. The Existence of God - Second Edition. Oxford: Oxford University Press, p. 311.
} 
não foi o que causou a percepção e assim nossa crença acerca desse objeto com base na percepção se torna infundada ${ }^{17}$.

O princípio de testemunho tem o papel de justificar não a crença na própria percepção, mas no relato de percepções tidas por outras pessoas, uma das fontes mais comuns das informações que julgamos ter sobre o que há. Segundo Swinburne, se não houver razão em contrário, estamos corretos em acreditar que aquilo que os outros nos dizem que eles perceberam provavelmente aconteceu ou, em outras palavras, as experiências dos outros são provavelmente como eles as relatam ${ }^{18}$. É bastante clara a semelhança estrutural entre os princípios de credulidade e testemunho. Ambos se pretendem princípios indutivos, postulando um determinado modo de justificar crenças que formamos ordinariamente e que não se pretendem afirmações necessariamente verdadeiras, mas que têm uma probabilidade de ser falsas. Além disso, ambos fundamentam as crenças correspondentes até que se tenha razão para se pensar diferente, num movimento comum de alegar "presunção de inocência". Por fim, os dois princípios se baseiam na tese de que ou aceitamos os correspondentes mecanismos de formação de crença (percepção e testemunho) ou nossa capacidade de formar qualquer crença acerca do mundo se reduz drasticamente, se é que não desaparece por completo. Assim, dado o caráter central e pervasivo desses modos de obter informação acerca do que se passa, a atitude de ceticismo em primeira instância quanto a eles acarreta uma enorme (senão total) privação de conteúdos de crença que normalmente pressupomos em nossas ações e que normalmente não questionamos. Sem dúvida, isso não constitui uma resposta cabal para o cético, pois ele ainda pode questionar o direito que temos de defender esses conteúdos informativos que pressupomos em nossas ações. Mas, provavelmente, não há resposta cabal contra o ceticismo epistemológico. Podemos dizer que há nas próprias ações do cético o reconhecimento tácito do uso dessas fontes de informação e que, consequentemente, só resta a ele não proferir qualquer sentença, ou seja, o silêncio. Isso não desmerece o valor dos questionamentos céticos no sentido de forçarem uma melhor elaboração filosófica das bases de justificação de nossas crenças. No entanto, se a questão é como podemos saber em que grau nossas crenças estão corretas, a adoção de uma posição cética ab initio não parece nos levar a lugar algum.

Considerados esses elementos da teoria de justificação epistêmica, Swinburne sugere uma determinada concepção de experiência religiosa para então se dedicar à aplicação desses conceitos em sua epistemologia da percepção de Deus. Embora admita a ocorrência de vários tipos de experi-

\footnotetext{
${ }_{17}$ SWINBURNE, Richard. The Existence of God - Second Edition. Oxford: Oxford University Press, p. 314.

${ }_{18}$ SWINBURNE, Richard. The Existence of God - Second Edition. Oxford: Oxford University Press, p. 322.
} 
ência classificáveis como religiosas, Swinburne se concentra na experiência teísta e considera "experiência religiosa" como um acontecimento mental de algo que parece (no sentido epistêmico, de levar o sujeito a formar uma crença com base na percepção) ser Deus estando ali ou fazendo algo ${ }^{19}$. Sua proposta é de aplicar o princípio de credulidade às percepções teístas e, por meio dos princípios de credulidade e testemunho, conseguir, mesmo partindo de uma descrição interna da experiência religiosa, um forte indício em favor da crença de que Deus existe.

\section{Problemas no Argumento da Experiência Religiosa de Swinburne}

A aplicação do princípio de credulidade à experiência religiosa exige que avaliemos se as condições nas quais se deram a experiência permitem considerá-la genuína ou não e aqui aparecem vários problemas na proposta de Swinburne. Em primeiro lugar, cabe discutir seu pressuposto de que há uma analogia forte entre a experiência sensorial e a experiência religiosa. Para Swinburne, se caímos num "atoleiro cético" quando não usamos o princípio de credulidade para as percepções sensoriais, é preciso um bom argumento para se negar o mesmo tratamento para a experiência religio$\mathrm{sa}^{20}$. Assim, cabe analisar se as condições pelas quais se diz que, apesar de parecer ao sujeito da experiência que Deus estava presente como causa de sua percepção, isso não era o caso realmente, ou seja, cabe discutir se há razões para se duvidar em geral da autenticidade das experiências que se afirmam ser de Deus.

O primeiro questionamento quanto à aplicação do princípio de credulidade à experiência religiosa diz respeito à confiabilidade do sujeito ou das condições nas quais acontecem tais experiências. Swinburne sustenta que, embora possa haver problemas desse tipo em alguns casos, a maioria das pessoas que afirma ter tido percepções teístas é confiável em seus relatos perceptuais e não se pode dizer que haja problemas nas condições nas quais elas tenham essas percepções a ponto de inviabilizar sua autenticidade ${ }^{21}$. Porém, em vista da avaliação que autores como William James ${ }^{22}$ fazem das tendências psicopatológicas dos que passam por esse tipo de experiência, talvez a avaliação de Swinburne seja otimista demais. Se são pessoas que

\footnotetext{
${ }^{19}$ SWINBURNE, Richard. The Existence of God - Second Edition. Oxford: Oxford University Press, p. 295.

${ }^{20}$ SWINBURNE, Richard. The Existence of God - Second Edition. Oxford: Oxford University Press, p. 304, nota 10.

${ }^{21}$ SWINBURNE, Richard. The Existence of God - Second Edition. Oxford: Oxford University Press, p. 315.

${ }^{22}$ JAMES, William. The Varieties of Religious Experience. 1902.
} 
fogem à normalidade psíquica, nossa confiança nos relatos que elas fazem repousa não no funcionamento padrão de seu aparato perceptual, mas nos resultados marcantes e altamente valorizáveis que tais experiências acabam gerando em suas vidas. No entanto, esse primeiro desafio à aplicação do princípio de credulidade aos relatos de experiência religiosa não é, sem dúvida, o principal problema para a tese de Swinburne nesse assunto. Podemos até admitir que não há realmente uma contestação geral fundamentada da capacidade perceptiva e das condições de percepção daqueles que dizem ter tido tais experiências e que as observações de James não se aplicam a todos os sujeitos envolvidos nesse assunto.

O segundo problema diz respeito às circunstâncias concernentes às supostas percepções teístas até agora e que geram dúvidas quanto à sua legitimidade. Mais especificamente, temos aqui, por um lado, a pluralidade de descrições dadas em diferentes religiões àquilo que se manifesta numa experiência religiosa e, por outro lado, a própria possibilidade de se identificar Deus numa ocorrência assim. Para Swinburne, quanto à primeira faceta desse desafio, basta que o relato seja apresentado numa forma menos comprometida culturalmente para que se possa reconhecê-lo como um relato de uma percepção de Deus, tal como o concebe o monoteísmo tradicional23. Em relação à segunda faceta, para ele, é possível reconhecer Deus numa experiência religiosa uma vez que se esteja familiarizado com a descrição de seus atributos tradicionalmente reconhecidos, como a onipotência e a infinita bondade. Porém, embora algumas experiências de religiões não teístas possam ser reconstruídas como experiências de Deus, elas podem se tornar irreconhecíveis se forem retiradas de um contexto cultural que seja radicalmente diferente do monoteísmo. Além disso, a redução do pluralismo religioso a um mínimo denominador comum geral não atende ao propósito de Swinburne, pois ele não está falando da percepção de uma "realidade última", mas de algo muito mais específico e conceitualmente carregado como o Deus do monoteísmo tradicional.

A terceira questão refere-se ao problema de se Deus estava mesmo presente para causar a percepção teísta e a quarta objeção questiona se, mesmo que Deus estivesse presente, a percepção não teria sido causada por outra causa. Swinburne responde a esses desafios basicamente com a tese de que eles só seriam efetivos se provassem que Deus não existe para estar presente ou para ser causa de uma experiência religiosa ${ }^{24}$. Uma vez que não há ainda um argumento assim com força suficiente, permanece intacta a possibilidade de que as alegadas experiências teístas sejam de fato de Deus e possam

\footnotetext{
${ }^{23}$ SWINBURNE, Richard. The Existence of God - Second Edition. Oxford: Oxford University Press, p. 316.

${ }^{24}$ SWINBURNE, Richard. The Existence of God - Second Edition. Oxford: Oxford University Press, p. 319 e 320.
} 
ser usadas como um forte indício num argumento indutivo em favor do teísmo. Contudo, as respostas de Swinburne aos desafios mostram apenas a possibilidade de que uma alegada experiência teísta se torne autêntica por meio do princípio de credulidade. Considerando que há muitas explicações que não apelam para a existência de Deus para explicar esses relatos de experiência religiosa, mas os reduzem a causas meramente psicológicas, sociológicas ou culturais, fica difícil aceitar que tenhamos aqui um argumento aceitável por todos em favor do teísmo. Em outras palavras, o problema é que Swinburne quer construir um argumento indutivo que convença o cético, ou seja, que seja sem dúvida a melhor opção explicativa, mas o cético tem a possibilidade de explicar aquelas ocorrências de forma naturalista e, assim, o máximo que ele consegue é uma espécie de "empate" na argumentação, ou seja, mostrar que é possível explicar essas ocorrências com base no teísmo também, o que é muito menos que ele pretendia. Uma saída desse impasse seria mostrar que o naturalismo como tese metafísica, ou seja, sobre o que consiste a realidade em termos últimos é muito menos fundamentado que o teísmo. Há uma corrente de argumentação - ainda minoritária na filosofia atual, porém - se formando nesse sentido ${ }^{25}$, mas essa seria outra linha de argumentação.

Por fim, a própria analogia entre a percepção teísta e a percepção sensorial suposta no argumento de Swinburne, que mencionamos acima, parece bastante fraca. Ele mesmo reconhece que há grandes diferenças entre ambas, ao afirmar que Deus só se manifesta a quem Ele escolhe se manifestar, o que significa que normalmente as experiências religiosas são percepções privadas e não eventos publicamente atestáveis ${ }^{26}$. Isso significa, por um lado, que o fato de um indivíduo que estava próximo do sujeito da experiência religiosa não ter captado coisa alguma não conta contra o relato dessa experiência e, por outro lado, que não se podem repetir as condições nas quais se dá uma revelação do sagrado. Além disso, experiências religiosas não envolvem o uso de nenhum dos cinco órgãos sensórios comuns, $\mathrm{o}$ que exige alguma elaboração acerca de como chegamos a captar aquilo a que elas se referem. O próprio fato de que não basta que nosso aparato perceptual seja afetado para que uma experiência tenha caráter religioso, mas se faz necessário que essa ocorrência afete o sujeito de uma forma que este a veja como significativa para sua relação com Deus, torna esse tipo de experiência bastante peculiar, essencialmente ligada a uma determinada concepção de mundo e não uma base comum, capaz de prover um argumento indutivo aceitável por todos.

${ }^{25}$ Dois exemplos são: REA, Michael. World Without Design - The Ontological Consequences of Naturalism. Oxford/New York: Oxford University Press, 2002; PLANTINGA, Alvin. Where the Conflict Really Lies - Science, Religion and Naturalism. Oxford/New York: Oxford University Press, 2011.

${ }^{26}$ SWINBURNE, Richard. The Existence of God - Second Edition. Oxford: Oxford University Press, p. 297-8. 


\section{Conclusão}

As dificuldades apontadas acima para um argumento em favor do teísmo com base na experiência religiosa, tal como proposto por Swinburne, podem ser respondidas de duas maneiras básicas. Por um lado, os problemas podem ser todos anulados (ou ao menos, significativamente enfraquecidos) chamando-se atenção para o papel desempenhado pelo argumento na proposta desse autor. Por outro lado, uma resposta a esses questionamentos pode indicar uma função alternativa para a experiência religiosa no projeto de justificação da crença em Deus.

Na proposta de reformulação da teologia natural em bases indutivas e probabilísticas de Swinburne, nenhum argumento deve ser visto de modo isolado, mas sim como parte de uma grande inferência cumulativa. Cada argumento isoladamente é como um balde furado, mas se você puser um balde furado embaixo do outro e se eles se ajustarem de modo tal que o buraco de um seja coberto pelo balde seguinte, é possível que o conjunto total acabe segurando água. Dito de outro modo, uma inferência cumulativa pode ter força probativa mesmo que cada um de seus argumentos individualmente não seja forte o suficiente para fundamentar a hipótese que se está avaliando.

$\mathrm{O}$ argumento da experiência religiosa tem um papel estratégico na inferência geral proposta por Swinburne. Trata-se do argumento decisivo, que vem ao final de uma sequência de argumentos que se acumulam, tendo como indícios aspectos da realidade que ou são pressupostos pela explicação científica ou exigiriam uma complicação excessiva da ciência para ser explicados. É depois de apresentar o teísmo como a melhor explicação para fenômenos como a existência do universo, o fato de que há ordem nesse universo físico, que há seres conscientes, e que o mal no mundo e a ocultação de Deus não são suficientes para diminuir o valor dos outros argumentos - é só depois de toda essa sequência que o argumento da experiência religiosa entra.

Assim, se todo o processo inferencial anterior for bem sucedido, o argumento da experiência religiosa já estará bem amparado, a ponto de que os problemas apontados ao final da seção anterior já não serão tão graves. Se for mesmo provável que Deus existe em vista dos outros argumentos, as possibilidades de erro perceptual, de dificuldade de identificação do objeto da percepção ou de analogia fraca entre percepção sensorial e experiência religiosa não serão suficientes para eliminar qualquer potencial de confirmação desse indício em favor da hipótese teísta. A essas alturas, a hipótese já terá uma probabilidade prévia suficientemente alta para se mostrar como uma boa explicação para o fenômeno relatado por aqueles que alegam ter tido experiências religiosas. Além disso, a maior probabilidade prévia do teísmo em relação a sua principal explicação rival - o 
naturalismo materialista cientificista - indicará que há uma probabilidade não negligenciável de que as experiências religiosas se refiram a Deus. Desse modo, embora possa haver dúvida a respeito de um ou outro relato isoladamente, o conjunto dos relatos de experiências religiosas ao longo de séculos pode ser tomado como um indício que aumenta a probabilidade do teísmo como hipótese explicativa.

Por outro lado, é possível manter o esquema inferencial bayesiano e usar a experiência religiosa de outro modo no processo de argumentação em favor do teísmo. O fato de que a experiência religiosa é aceita por um dos grupos envolvidos no debate acerca da racionalidade do teísmo, mas não pelo outro, pode deixar de ser um problema se, ao invés de uma premissa em um argumento indutivo, ela for fator de atribuição de diferentes valores de probabilidade prévia do qual partem os dois grupos principais. Em outras palavras, para um bom argumento indutivo, as premissas devem ser mais aceitáveis que a conclusão. Sendo a experiência religiosa algo controverso para participantes naturalistas no debate, ela se torna um indício argumentativo fraco. No entanto, se a colocarmos como parte do conhecimento de fundo inicial (representado por " $\mathrm{k}$ " nas fórmulas do teorema acima) dos teístas, mas não dos naturalistas, o problema deixa de existir. Nesse caso, teríamos que, em função de diferentes conjuntos de crenças de fundo iniciais, teístas e naturalistas vão atribuir valores iniciais diferentes à hipótese da existência de Deus. Não há nada de errado nisso, ao contrário, é exatamente o que se espera em um debate no qual os participantes divergem inicialmente ao mesmo tempo em que estão dispostos a mudar de ideia em vista de bons argumentos. $\mathrm{O}$ modelo bayesiano de argumentação probabilística permite exatamente isto: que contendores em um debate partam de estimativas iniciais distintas, mas que possam mudar de ideia ao longo da discussão, à medida que os indícios sejam reconhecidos conjuntamente como aumentando ou diminuindo suas probabilidades prévias da hipótese em avaliação. $\mathrm{O}$ teorema de Bayes permite uma convergência de opiniões ao longo da discussão, desde que os debatedores não atribuam valores extremos (0 ou 1) à hipótese em avaliação e desde que partilhem o mesmo grau de crença em relação aos outros indícios considerados nos argumentos do debate $^{27}$. Desse modo, a experiência religiosa não entraria ao final, como argumento decisivo, mas que depende de outros anteriores para fundamentar o teísmo em bases mais sólidas. Ela entraria no início, como parte da bagagem de crenças iniciais de um dos grupos de debatedores e que podem mudar com a discussão.

\footnotetext{
${ }^{27}$ Um interessante exemplo dessa convergência de probabilidades prévias inicialmente divergentes aparece em PHILLIPS, Lawrence. Bayesian Statistics for Social Scientists. Londres: Thomas Nelson and Sons, 1973, p. 76-7, que é também uma excelente introdução ao bayesianismo para quem tem pouco conhecimento matemático. Embora o livro se refira à estatística bayesiana, aplica-se também à probabilidade epistêmica.
} 
Como quer que ela seja incluída no debate acerca da existência de Deus, a experiência religiosa adquiriu um papel relevante na filosofia analítica da religião contemporânea. Um autor central a esse respeito é William Alston $^{28}$, que advoga um papel mais direto para a experiência religiosa na justificação da crença teísta, análogo ao que a percepção sensorial tem na justificação das crenças sobre o mundo externo. Penso que a proposta de Alston pode ser incluída na segunda alternativa de solução apresentada nesta conclusão, mas não houve espaço para desenvolver isso aqui.

Em todo caso, além de parte da vida religiosa subjetiva do crente, após esse debate, a experiência religiosa passou a ter um papel cognitivo objetivo talvez não pensado anteriormente na história da filosofia.

Endereço do Autor:

SQS 303, Bloco J, Apto. 201

70336-100 Brasília - DF

agnaldocp@unb.br

${ }^{28}$ ALSTON, William. Perceiving God - The Epistemology of Religious Experience. Ithaca, NY: Cornell University Press, 1991. 